\title{
PENGUNGKAPAN MODAL INTELEKTUAL PERGURUAN TINGGI VOKASI DI INDONESIA BERDASARKAN INSTRUMEN AKREDITASI PROGRAM STUDI (IAPS) 4.0
}

\author{
Lilik Intan Herawati \\ intanlilik16@gmail.com \\ Ihyaul Ulum \\ Ahmad Juanda \\ Dhaniel Syam \\ Program Studi Akuntansi Universitas Muhammadiyah Malang
}

\begin{abstract}
The purpose of this study is to identify and describe the quality of intellectual capital disclosure (ICD) of vocational colleges in Indonesia. The ICD framework used is the Intellectual Capital Framework (ICF) of Higher Education in Indonesia based on the Study Program Accreditation Instrument (IAPS) 4.0 developed by Ulum (2019). This framework consists of 60 IC items, which are divided into three main components, namely human capital (30 items), structural capital (18 items), and relational capital (12 items). Data analysis was performed using a six ways numerical coding system which is a content analysis technique. In this technique, the information presented on the college website is given grades ranging from ' $O$ ' (not disclosed) to ' 5 ' (expressed in graphic/image format). The results indicate that IC disclosure patterns chosen by vovational colleges in Indonesia are mostly in the form of pictures/graphics and narratives. However, the number of undisclosed IC items was very dominant $(47.40 \%)$. The most disclosed information is about structural capital (66\%). The next component is the relational capital. While the information on human capital was only disclosed as much as $36 \%$ from 30 items.
\end{abstract}

Key words: IAPS 4.0; intellectual capital; vocational universities.

\begin{abstract}
ABSTRAK
Tujuan Penelitian ini adalah untuk mengidentifikasi dan mendeskripsikan kualitas pengungkapan modal intelektual (ICD) perguruan tinggi vokasi di Indonesia. Framework ICD yang digunakan adalah Intellectual Capital Framework (ICF) Perguruan Tinggi di Indonesia berdasarkan Instrumen Akreditasi Program Studi (IAPS) 4.0 yang dikembangkan oleh Ulum (2019). Framework ini terdiri dari 60 item IC, yang terbagi dalam tiga komponen utama, yaitu human capital (30 item), structural capital (18 item), dan relational capital (12 item). Analisis data dilakukan dengan six ways numerical coding system yang merupakan teknik analisis isi. Dalam teknik ini, informasi yang disajikan di website perguruan tinggi diberikan nilai mulai dari '0' (tidak diungkapkan) sampai '5' (Diungkapkan dalam format grafik atau gambar). Hasil penelitian menunjukkan bahwa pola pengungkapan IC yang dipilih oleh perguruan tinggi vovasional di Indonesia sebagian besar dalam bentuk gambar atau grafik dan narasi. Namun, jumlah item IC yang tidak diungkapkan sangat dominan (mencapai angka $47,40 \%)$. Informasi yang paling banyak diungkapkan adalah tentang structural capital $(66 \%)$. Komponen selanjutnya adalah relational capital. Sedangkan informasi tentang human capital hanya diungkapkan sebanyak $36 \%$ dari 30 item.
\end{abstract}

Kata-kunci: IAPS 4.0; intellectual capital; perguruan tinggi vokasi

\section{PENDAHULUAN}

Modal intelektual atau Intellectual Capital (IC) mulai banyak diteliti oleh berbagai macam peneliti dan dilakukan di beberapa negara sejak tahun 1980-an hingga saat ini. Hal ini terjadi karena mulai 
banyaknya kesadaran dan pemahaman mengenai modal intelektual. Pada dasarnya modal intelektual merupakan suatu aset tak berwujud yang berhubungan dengan pengetahuan yang dimiliki suatu organisasi. IC adalah aset tak berwujud. IC dapat berbentuk kepercayaan pelanggan, brand image, pengendalian distribusi, budaya organisasi, keterampilan manajemen, dan sebagainya (Itami dan Roehl 1987). Sirojudin dan Nazaruddin (2014) mengemukakan bahwa para pelaku bisnis mulai menyadari jika kesuksesan dalam berbisnis tidak hanya mengandalkan aset berwujud saja melainkan juga mengandalkan aset tak bewujud (intangible assets). Anatan (2006) mengatakan bahwa Aset SDM penting bagi perusahaan karena aset ini merupakan sumber inovasi dan pembaharuan strategik yang diperoleh baik dari penelitian laboratorium, reenginering proses baru, perbaikan keterampilan personal.

Tower et al. (2008) menyatakan perguruan tinggi memiliki peranan penting dalam membimbing langkah masyarakat pada perbaikan kesejahteraan melalui kemajuan dalam ilmu pengetahuan, humaniora, teknologi dan interaksi sosial. Perguruan tinggi di Indonesia bukan hanya universitas, melainkan juga terdapat perguruan tinggi vokasi, sekolah tinggi dan pendidikan tinggi lainnya yang sederajat.

Di sejumlah negara Eropa, selain harus menyusun laporan keuangan, perusahaan publik harus juga menyajikan laporan tentang pengelolaan aset tak berwujud mereka (lihat misalnya: Moolman 2010; European Commission 2007; Andriessen 2005; Starovic dan Marr 2003; Mouritsen et al. 2003; Bukh et al. 2001). Bahkan, universitas dan organisasi-organisasi nonprofit, belakangan juga mulai rajin mengungkapkan pengelolaan aset takberwujud yang mereka miliki (misalnya: Sultanova et al., 2018; Cricelli et al., 2018; Bisogno et al., 2018; Ramirez dan Gordillo 2014; Leitner et al., 2014; Ramírez 2013a, 2013b; Antonella dan Stefania 2011; Bezhani 2010; Sánchez et al., 2009). Intangible assets ini biasa juga disebut dengan istilah intellectual capital (IC). Beberapa peneliti memberikan definisi dan pengertian yang beragam tentang IC. Stewart (1997) mendefinisikan IC sebagai jumlah dari segala sesuatu yang ada di organisasi yang dapat membantu orgamionisasi untuk berkompetisi di pasar, meliputi intellectual material pengetahuan, informasi, pengalaman, dan intellectual property yang dapat digunakan untuk menciptakan kesejahteraan.

Brooking (1996) menyatakan bahwa IC adalah istilah yang diberikan kepada kombinasi dari aset takberwujud, properti intelektual, karyawan, dan infrastruktur yang memungkinkan organisasi untuk dapat berfungsi. Dalam definisi ini jelas tersirat bahwa IC tidak hanya sekedar tentang sumber daya manusia (human capital/HC), HC hanyalah salah satu komponen dari IC.

IC mulai dikenal di Indonesia ketika munculnya PSAK No.19 tentang aset tak berwujud. Aset takberwujud diartikan sebagai aset nonmoneter teridentifikasi tanpa wujud fisik (PSAK No. 19, revisi tahun 2014). Karena modal intelektual bersifat tidak berwujud yang artinya output dari aset ini tidak bisa dilihat secara langsung bentuknya, maka banyak yang beranggapan bahwa modal intelektual masih sulit di pahami. Namun, ketika modal intelektual dapat dianalisis dan diungkapkan secara relevan, maka ini dapat menjadi nilai tambah dan sumber daya (aset) baru bagi organisasi agar mampu lebih meningkatkan daya saingnya masing-masing.

Sanchez dan Elena (2006) menyatakan bahwa Universitas dan Perguruan Tinggi dianggap aktor kelembagaan kritis dalam sistem inovasi nasional. Peran utama universitas adalah sebagai pengembang dan penyalur ilmu pengetahuan yang sudah di dapatkan pada jenjang sebelumnya. Pada faktanya input dan output utama yang dihasilkan oleh universitas dan perguruan tinggi tidak berwujud, instrumen dalam mengelola dan mengukurnya menjadi terbatas (Cañibano dan Sánchez 2004). 
Maka dari itu, peran utama dari pengungkapan modal intelekual sangat diperlukan dalam hal ini untuk mengetahui sejauh mana aset tak berwujud dalam hal ini modal intelektual diungkapkan secara relevan oleh perguruan tinggi di Indonesia.

Mulai 1 April 2019, Badan Akreditasi Nasional (BAN) Perguruan Tinggi (PT) memberlakukan instrumen akreditasi baru, IAPS (Instrumen Akreditasi Program Studi) 4.0. Aspek paling mendasar dari perubahan instrumen ini adalah terkait dengan jumlah kriteria (pada instrumen sebelumnya disebut standar). IAPS 4.0 menggunakan 9 kriteria, sementara sebelumnya hanya menggunakan 7 standar. Selain memecah standar nomor 7 menjadi 2 kriteria (penelitian dan pengabdian kepada masyarakat), IAPS 4.0 juga memunculkan satu kriteria baru yaitu luaran dan capian tridharma.

IAPS 4.0 terdiri atas dua bagian besar, yaitu LED (Laporan Evaluasi Diri) dan LKPS (Laporan Kinerja Program Studi). LED menggambarkan status dan analisis capaian dari masing-masing kriteria. Unit pengelola program studi diharapkan mampu mengenali kekuatan yang dimiliki serta aspek apa saja yang perlu diperbaiki. Sementara LKPS memuat capaian indikator kinerja program studi yang secara bertahap diintegrasikan dengan PD-DIKTI.

Penelitian ini penting dilakukan mengingat bahwa Perguruan Tinggi Vokasi memiliki fungsi utama yang sama dengan Perguruan Tinggi Non-Vokasi yaitu sebagai penyalur ilmu untuk masyarakat. Di samping itu, penelitian ini juga memberikan pengetahuan baru mengenai pengungkapan modal intelektual yang dilakukan oleh Perguruan Tinggi Vokasi yang ada di Indonesia berdasarkan instrumen akreditasi terbaru yang dikembangkan oleh BAN-PT yaitu Instrumen Akreditasi Program Studi (IAPS) 4.0.

\section{METODE PENELITIAN}

Penelitian ini menggunakan jenis penelitian deskriptif. Penelitian deskriptif merupakan pengungkapan, penjelasan, atau penggambaran suatu fenomena secara sistematis dan akurat mengenai fakta-fakta, sifat-sifat dan hubungan antara komponenkomponen yang bersangkutan dan yang diselidiki (Ulum dan Juanda 2016). Penelitian ini bertujuan untuk memberikan gambaran mengenai pengungkapan modal intellectual pada 50 perguruan tinggi vokasi terbaik di Indonesia menurut Kemenristekdikti.

Jenis data pada penelitian ini adalah data kualitatif. Berdasarkan cara memperolehnya, data yang digunakan untuk mendukung penelitian ini adalah data sekunder. Data sekunder adalah data yang didapatkan atau digunakan oleh pihak yang bukan pengolah utamanya.

Teknik perolehan data pada penelitian ini menggunakan teknik dokumentasi, data diperoleh dari official website masing-masing perguruan tinggi vokasi yang menjadi objek penelitian.

Unit analisis pada penelitian ini adalah 50 website perguruan tinggi vokasi versi kemenristekdikti 2019. Komponen-komponen dikonstruksikan oleh (Ulum 2019) yang merupakan modifikasi dari Leitner (2002). Modifikasi tersebut disesuaikan dengan standar perguruan tinggi di Indonesia yang diatur oleh Badan Akreditasi Nasional Perguruan Tinggi (BAN-PT).

Komponen IC pendidikan tinggi telah dikategorikan dalam beragam cara. Namun, klasifikasi tripartit tidak diragukan lagi yang paling banyak diterima dalam berbagai literatur (Leitner 2004; Sánchez dan Elena 2007; Cañibano dan Sánchez 2009; Sánchez et al., 2009; Secundo et al., 2010). IC direpresentasikan sebagai konstruksi dari tiga komponen dasar dan saling terkait berikut ini (Ramirez dan Gordillo 2014):

1) Human capital: jumlah pengetahuan eksplisit dan terpendam dari staf pendidikan tinggi (dosen, pejabat struktural, tenaga kependidikan), yang diperoleh melalui pendidikan formal dan non-formal. 
2) Structural capital: pengetahuan eksplisit yang berkaitan dengan proses diseminasi internal, komunikasi dan pengelolaan atas pengetahuan ilmiah dan pengetahuan teknis di pendidikan tinggi. Structural capital dapat dibagi menjadi:

a. Organisational capital: lingkungan operasional yang berasal dari interaksi antara penelitian, manajemen dan proses organisasi, rutinitas organisasi, budaya dan nilai-nilai perusahaan, prosedur internal, kualitas dan ruang lingkup sistem informasi, dan lain-lain.

b. Technological capital: sumber daya teknologi yang tersedia di internet institusi pendidikan tinggi, seperti sumber daya bibliografi dan dokumenter, arsip, pengembangan teknis, paten, lisensi, perangkat lunak, basis data, dan lain-lain.

Relational capital: koleksi ekstensif hubungan ekonomi, politik dan kelembagaan yang dibangun dan dikembangkan antara pendidikan tinggi dengan mitra nonakademiknya (misalnya: perusahaan, organisasi nirlaba, pemerintah daerah, dan masyarakat pada umumnya). Ini juga mencakup persepsi yang dimiliki orang lain tentang institusi pendidikan tinggi: citra, daya tarik, keandalan, dan lain-lain.

Ketiga komponen inilah yang digunakan dalam framework ICD berbasis IAPS 4.0. Secara keseluruhan, framework ini terdiri dari 60 item yang terbagi dalam tiga kategori, yaitu human capital (30 item), structural capital (18 item), dan relational capital (12 item) (lihat Tabel 1).

Tabel 1

Intellectual Capital Framework Perguruan Tinggi berdasarkan IAPS 4.0

\begin{tabular}{ll}
\hline \multicolumn{2}{c}{ Human Capital } \\
HC1 & Jumlah Dosen \\
HC2 & Kualifikasi Dosen \\
HC3 & Kompetensi Dosen \\
HC4 & Beban Kerja Dosen \\
HC5 & Jumlah Dosen dengan Pendidikan S3 \\
HC6 & Jumlah Dosen yang memiliki kepangkatan Guru Besar \\
HC7 & Jumlah Dosen yang memiliki kepangkatan Lektor Kepala \\
HC8 & Jumlah Dosen yang memiliki Sertifikat Kompetensi/Pendidik/Industri \\
HC9 & Jumlah Dosen Tidak Tetap \\
HC10 & Jumlah Mahasiswa Aktif \\
HC11 & Jumlah Mahasiswa Baru \\
HC12 & Jumlah Mahasiswa Transfer \\
HC13 & Jumlah Mahasiswa Luar Negeri \\
HC14 & Jumlah Tenaga Kependidikan \\
HC15 & Kualifikasi Tenaga Kependidikan \\
HC16 & Kompetensi Tenaga Kependidikan \\
\hline
\end{tabular}
Elemen intellectual capital

HC17 Beban Kerja Tenaga Kependidikan

HC18 Pengakuan atas Kepakaran Dosen

HC19 Publikasi Ilmiah Dosen

HC20 Karya Ilmiah Dosen yang Disitasi

HC21 Produk/Jasa Dosen yang Diadopsi oleh Industri

HC22 Payung Penelitian Dosen-Mahasiswa 
HC23 Payung Pengabdian kepada Masyarakat Dosen-Mahasiswa

HC24 Prestasi Akademik Mahasiswa

HC25 Prestasi Non-Akademik Mahasiswa

HC26 Daya Saing Lulusan*

HC27 Kinerja Lulusan**

HC28 Publikasi Ilmiah Dosen bersama Mahasiswa

HC29 Jumlah Artikel Dosen bersama Mahasiswa yang Disitasi

HC30 Produk/jasa Dosen bersama Mahasiswa yang Diadopsi Masyarakat/Industri

Structural Capital

SC1 Visi, Misi, Tujuan (VMT)

SC2 Strategi Pencapaian VMT

SC3 Sistem Tata Pamong (good governance)

SC4 Sistem Penjaminan Mutu

SC5 Sistem Seleksi Mahasiswa

SC6 Layananan Kemahasiswaan***

SC7 Sistem Pengembangan SDM****

SC8 Dana Penelitian Dosen (sumber internal)

SC9 Dana Pengabdian kepada Masyarakat Dosen (sumber internal)

SC10 Sarana dan Prasarana Tridharma

SC11 Sistem Informasi Akademik

SC12 e-Learning

SC13 Sistem Informasi Perpustakaan

SC14 Sistem Informasi Penelitian

SC15 Sistem Informasi

SC16 Kurikulum

SC17 Sistem Pembelajaran

SC18 Standar Penelitian dan Pengabdian kepada Masyarakat

\section{Relational Capital}

RC1 Kerjasama Internasional bidang Pendidikan

RC2 Kerjasama Internasional bidang Penelitian

RC3 Kerjasama Internasional bidang Pengabdian kepada Masyarakat

RC4 Kerjasama Nasional bidang Pendidikan

RC5 Kerjasama Nasional bidang Penelitian

RC6 Kerjasama Nasional bidang Pengabdian kepada Masyarakat

RC7 Kerjasama Regional bidang Pendidikan

RC8 Kerjasama Regional bidang Penelitian

RC9 Kerjasama Regional bidang Pengabdian kepada Masyarakat

RC10 Jumlah Dana Kerjasama Pendidikan

RC11 Jumlah Dana Kerjasama Penelitian

RC12 Jumlah Dana Kerjasama PkM

\section{Keterangan:}

* waktu tunggu lulusan untuk bekerja (mendapatkan pekerjaan atau berwirausaha) yang relevan dengan bidang studi dan kesesuaian bidang kerja lulusan dengan bidang studi

** tingkat kepuasan pengguna lulusan dan tingkat/ukuran tempat kerja/berwirausaha lulusan 
*** bimbingan dan konseling, pengembangan nalar, minat dan bakat, pengembangan soft skills, layanan beasiswa, layanan kesehatan, bimbingan karir, dan kewirausahaan.

**** perencanaan, rekrutmen, seleksi, penempatan, pengembangan, retensi, pemberhentian, dan pension.

Teknik analisis data menggunakan analisis isi (content analysis). Content analysis diartikan sebagai salah satu cara telaah data yang berusaha menguraikan data secara objektif, berurutan dan berbentuk kualitatif. Analisis ini bertujuan untuk memahami makna suatu teks secara konsisten. Analisis isi ini banyak digunakan untuk menganalisis teks dalam media. Analisis ini berusaha memahami data bukan sebagai peristiwa fisik, tetapi sebagai gejala simbolik untuk mengungkapkan makna yang terkandung dalam sebuah teks, dan memperoleh pemahaman terhadap pesan yang direpresentasikan. Analisis isi yang digunakan dalam penelitian ini adalah six ways numberical coding system. Six ways numerical coding system menilai kualitas pengungkapan (bukan hanya kuantitas pengungkapan yang biasanya menggunakan dummy variable) melalui website, dengan kriteria sebagai berikut:

Tabel 2

Six Ways Numerical Coding System

\begin{tabular}{cl}
\hline \hline Kode & \multicolumn{1}{c}{ Jika } \\
\hline 0 & Item tidak diungkapkan \\
1 & Terdapat judul item, tetapi tidak ada isinya \\
2 & Item diungkapkan dalam format narasi \\
3 & Item diungkapkan dalam format angka \\
4 & Item diungkapkan dalam format satuan moneter \\
5 & Item diungkapkan dalam format grafik/chart/gambar \\
\hline
\end{tabular}

\section{ANALISIS DAN PEMBAHASAN}

Sudah banyak pengertian tentang modal intelektual yang di definisikan oleh beberapa ahli. Sebagian besar peneliti membagi intellectual capital menjadi tiga elemen utama yaitu: human capital, structural capital atau organizational capital, dan relational capital. Berdasarkan beberapa definisi tentang modal intelektual yang sudah banyak didefinisikan oleh beberapa ahli, dapat ditarik kesimpulan bahwa modal intelektual termasuk pada aset tak berwjud yang tak nampak bentuknya, tidak dapat dilihat secara kasat mata namun dapat meningkatkan nilai pada suatu organisasi dan perusahaan apabila dikelola dan diolah secara baik dan benar (Ulum 2015).

Secara garis besar elemen modal intelektual terdiri dari aspek humaniora dan infrastruktur yang mampu memberikan jalan kepada organisasi agar dapat berjalan sesuai dengan fungsi dan tujuan yang ingin dicapai. Komponen-komponen modal intelektual terdiri dari human capital, structural capital, dan relational capital (Bontis 1998).

Ulum dan Pratiwi (2012) menyatakan bahwa Human Capital merupakan kompetensi potensial yang dimiliki oleh masingmasing universitas, dimana pada komponen ini dijelaskan mengenai jumlah professor, dosen, staff dan jumlah yang prestasi yang dimiliki dosen. Human Capital merupakan sumber inovasi bagi suatu organisasi dan entitas. Untuk suatu organisasi agar mampu mencapai tujuan yang maksimal, maka elemen human capital juga harus di kelola dengan maksimal juga. 
Tabel 3

Rangkuman Konstruk dan Definisi IC

\begin{tabular}{|c|c|c|}
\hline Peneliti & Konstruk & Definisi IC \\
\hline Bontis (1996) & $\begin{array}{l}\text { Human capital } \\
\text { Structural capital } \\
\text { Relational capital }\end{array}$ & $\begin{array}{l}\text { IC adalah sumber daya yang menjadi modal } \\
\text { bagi organisasi untuk memenangkan persaingan }\end{array}$ \\
\hline $\begin{array}{l}\text { Roos \& Roos } \\
(1997)\end{array}$ & $\begin{array}{l}\text { Human capital } \\
\text { Structural capital }\end{array}$ & $\begin{array}{l}\text { IC adalah kumpulan aset tersembunyi yang } \\
\text { dimiliki organisasi, seperti brands, trademarks } \\
\text { dan patents serta aset-aset lainnya yang tidak } \\
\text { nampak pada laporan keuangan. IC adalah } \\
\text { sumber daya paling penting bagi organisasi } \\
\text { untuk mempertahankan keunggulan komptetif. }\end{array}$ \\
\hline $\begin{array}{l}\text { Stewart } \\
(1997)\end{array}$ & $\begin{array}{l}\text { Human capital } \\
\text { Structural capital } \\
\text { Customer capital }\end{array}$ & $\begin{array}{l}\text { IC adalah pengetahuan, informasi, properti } \\
\text { intelektual, dan pengalaman. }\end{array}$ \\
\hline $\begin{array}{l}\text { Edvinsson \& } \\
\text { Malone } \\
(1997)\end{array}$ & $\begin{array}{l}\text { Human capital } \\
\text { Structural capital } \\
\text { Customer capital }\end{array}$ & $\begin{array}{l}\text { IC merujuk kepada perbedaan antara nilai pasar } \\
\text { dan nilai buku perusahaan. }\end{array}$ \\
\hline Sveiby (1998) & $\begin{array}{l}\text { Personnel competence } \\
\text { Internal structure } \\
\text { External structure }\end{array}$ & $\begin{array}{l}\text { IC adalah pengetahuan yang dapat diubah } \\
\text { menjadi nilai. }\end{array}$ \\
\hline Bontis (1999) & $\begin{array}{l}\text { Human capital } \\
\text { Structural capital } \\
\text { Relational capital }\end{array}$ & $\begin{array}{l}\text { IC adalah penggunaan pengetahuan yang } \\
\text { efektif yang bertentangan dengan informasi. }\end{array}$ \\
\hline $\begin{array}{l}\text { Andriessen } \\
\& \text { Stem } \\
(2004)\end{array}$ & $\begin{array}{l}\text { Human resources } \\
\text { Organizational } \\
\text { resources Relational } \\
\text { resources }\end{array}$ & $\begin{array}{l}\text { IC adalah sumber daya takberwujud yang ada } \\
\text { pada suatu organisasi, yang menjadi } \\
\text { keunggulan organisasi, dan dapat menciptakan } \\
\text { keuntungan di masa yang akan datang. }\end{array}$ \\
\hline $\begin{array}{l}\text { Youndt et al. } \\
(2004)\end{array}$ & $\begin{array}{l}\text { Human capital } \\
\text { Organizational capital } \\
\text { Social capital }\end{array}$ & $\begin{array}{l}\text { IC adalah sekumpulan pengetahuan yang } \\
\text { memungkinkan organisasi untuk menjalankan } \\
\text { bisnis dan memenangkan persaingan. }\end{array}$ \\
\hline
\end{tabular}

\section{Sumber: Wang (2008)}

Walaupun elemen ini secara kasat mata susah diukur, namun output dari elemen human capital dapat diukur dan dilihat melalui pencapaian hasil. Menurut Raheja dan Raheja (1999) perbaikan sumber daya manusia untuk perusahaan tidak hanya disumbangkan oleh karyawan tetap tetapi juga oleh siswa dari pendidikan koperasi (koperasi) yang bekerja di perusahaanperusahaan ini. Ini artinya seluruh elemen intelektual baik itu tenaga pengajar maupun mahasiswa pada suatu unversitas mempunyai tugas yang sama untuk dapat memperbaiki dan menambah mutu intelektual guna untuk mencapai tujuan organisasi.

Termasuk dalam kategori HC adalah kriteria 'daya saing lulusan' dan 'kinerja lulusan'. Kedua elemen ini sesungguhnya merupakan dampak dari keberhasilan elemen-elemen yang lain. Elemen 'daya saing lulusan' mengukur waktu tunggu 
lulusan untuk bekerja (mendapatkan pekerjaan atau berwirausaha) yang relevan dengan bidang studi dan kesesuaian bidang kerja lulusan dengan bidang studi. Sementara elemen 'kinerja lulusan' terkait dengan tingkat kepuasan pengguna lulusan dan tingkat atau ukuran tempat kerja atau tempat berwirausaha lulusan.

Menurut Suhardjanto dan Wardhani (2010), structural capital merupakan kemampuan perusahaan dalam mendukung kinerja bisnis secara keseluruhan yang mencakup dua elemen penting, yaitu intellectual property dilindungi oleh hukum (paten, hak cipta, dan merk dagang) dan infrastructure asset merupakan elemen intellectual capital yang dapat diciptakan di dalam perusahaan atau dimiliki dari luar (budaya perusahaan, proses manajemen, sistem informasi, sistem jejaring). Jika komponen human capital misalnya seorang pengajar mempunyai tingkat intelektual yang tinggi dan didukung sisitem dan prosedur yang baik dalam hal ini hardware dan istem informasi yang baik dari structur capital, maka hal tersebut akan mampu meningkatkan produktivitas dari seorang karyawan tersebut.

Kategori structural capital (SC) terdiri dari 18 item yang terkait dengan pengetahuan eksplisit yang berkaitan dengan proses diseminasi internal, komunikasi dan pengelolaan atas pengetahuan ilmiah dan pengetahuan teknis di pendidikan tinggi (Ramirez dan Gordillo 2014). Termasuk dalam kelompok ini adalah 'Layananan Kemahasiswaan' meliputi bimbingan dan konseling, pengembangan nalar, minat dan bakat, pengembangan soft skills, layanan beasiswa, layanan kesehatan, bimbingan karir, kewirausahaan dan 'Sistem Pengembangan SDM' (meliputi perencanaan, rekrutmen, seleksi, penempatan, pengembangan, retensi, pemberhentian, dan pensiun).

Komponen relational capital merupakan suatu hubungan yang dijalankan oleh organisasi dalam hal ini yaitu universitas maupun perguruan tinggi dalam bidang ekonomi, politik dan hubungan kelembaga- an yang dikembangkan antara universitas dan nonakademik, perusahaan, organisasi nirlaba, pemerintah, dan juga pada masyarakat umum. Komponen ini juga dapat diartikan sebagai hubungan antara perusahaan ataupun organisasi dengan mitranya. Menurut Suwarti et al. (2016) relational capital dapat muncul dari berbagai bagian diluar lingkungan perusahaan yang dapat menambah nilai bagi perusahaan tersebut. Sedangkan dalam penelitian yang dilakukan Maharani dan Faisal (2019) relational capital terkait dengan hubungan eksternal perusahaan, seperti hubungan dengan pelanggan, pemasok, mitra, dan juga masyarakat lokal.

Kelompok relational capital (RC) terdiri dari 12 item. RC dalam konteks ini hanya fokus pada kerjasama, baik regional, nasional, maupun internasional. Hal ini sebenarnya kurang ideal jika merujuk pada pendapat yang menyatakan bahwa RC merupakan koleksi ekstensif hubungan ekonomi, politik dan kelembagaan yang dibangun dan dikembangkan antara pendidikan tinggi dengan mitra non-akademiknya (Ramirez dan Gordillo 2014). RC juga harusnya mencakup persepsi yang dimiliki orang lain tentang institusi pendidikan tinggi: citra, daya tarik, keandalan, dan lainlain.

Nugroho (2012) mengatakan bahwa perusahaan-perusahaan melakukan pengungkapan intellectual capital karena berbagai alasan. Ada beberapa alasan yang di ungkapkan oleh para peneliti. Namun secara umum pengungkapan dilakukan agar dapat meningkatkan fungsi manajemen perusahaan dalam meningkatkan pelaporan eksternal. Kualitas intellectual capital disclosure yang tepat dan efektif pada suatu organisasi maupun perusahaan akan mampu membantu menciptakan kekayaan di masa depan. Hal ini dikarenakan aset tak berwujud pada perguruan tinggi jika dilaporkan secara tepat dan para pemangku kepentingan dapat memahami pelaporan tersebut dengan baik, maka hal itu mampu meningkatkan transparansi pelaporan yang 
akan berimbas pada penambahan nilai terhadap perguruan tinggi terkait. Harisnwati et al. (2017) mengungkapkan bahwa, pengungkapan modal intelektual belum banyak dilakukan oleh perusahaan dikarenakan masih belum adanya kesadaran pihak manajemen mengenai modal intelektual yang dimilikinya.

Data pada penelitian ini berupa data deskriptif. Data yang memberikan penjelasan berupa data kualitatif mengenai pengungkapan modal intelektual pada perguruan tinggi vokasi terbaik versi kemenristekdikti. Ber- dasarkan objek yang telah ditentukan maka untuk memperoleh hasil pengungkapan modal intelektual digunakanlah analisis isi (content analysis) pada setiap official website masing-masing perguruan tinggi vokasi terbaik versi kemenristekdikti. Penilaian untuk pengungkapan item pada setiap komponen menggunakan six ways numberical coding system. Penilaian tersebut digunakan untuk menganalisis 60 item pengungkapan modal intelektual yang terbagi menjadi 3 komponen yaitu komponen human capital, structural capital, dan relational capital.

Tabel 4

Statistik Deskriptif

\begin{tabular}{llccc}
\hline & Minimum & Maximum & Average & Std. Deviation \\
\hline ICD & 17.00 & 44.00 & 29.72 & 7.24 \\
\hline
\end{tabular}

Berdasarkan hasil perhitungan statistik deskriptif pada Tabel 4 menunjukkan bahwa dari 47 sampel perguruan tinggi vokasi di Indonesia versi Kemenristekdikti rata-rata pengungkapan modal intelektual sebesar 29.72 dengan nilai pengungkapan maksi mum 44 yang diungkapkan oleh Politeknik Negeri Pontianak dan nilai pengungkapan minimum 17 yang diungkapkan oleh Politeknik Manufaktur Ceper. Kemudian untuk nilai standar deviasi mencapai angka 7,24 Standar deviasi menunjukkan bagaimana penyebaran data.
Pada data ini, standar deviasi < 10 yang berarti bahwa penyebaran pengungkapan modal intelektual yang dilakukan oleh 47 Perguruan Tinggi Vokasi Indonesia bersifat homogen atau rata-rata yang di ungkapkan sebagian besar sama.

Setelah melakukan analisis berdasarkan 60 item penilaian yang ada dan pengungkapan diberikan nilai sesuai dengan six ways numberical coding system dan perhitungan yang telah dilakukan, maka hasil yang diperoleh sebagai berikut:

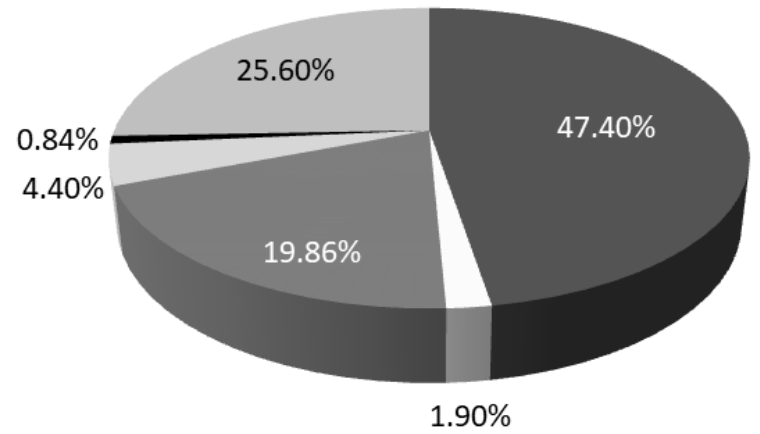

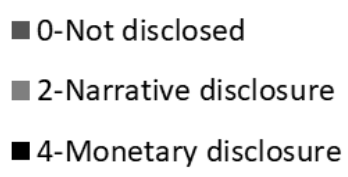

1-There is a title, but no content

3-Numerical disclosure

5-Images disclosure

Gambar 1

Format pengungkapan IC melalui website 
Setelah melakukan perhitungan terhadap penilaian item terhadap komponen yang diungkapkan, maka dari tabel diatas dapat ditarik kesimpulan bahwa item dengan nilai " 0 " atau item tidak diungkapakan yang memiliki prosentase paling tinggi yaitu sebesar $47,40 \%$ atau mendekati setengah persen dari modal intelektual tidak diungkapkan oleh perguruan tinggi vokasi. Kemudian item diungkapkan dengan format gambar, grafik atau chart memiliki prosentase $25,60 \%$. Kemudian item diungkapkan secara narasi memiliki prosentase pengungkapan sebesar 19,86\%. Untuk pengungkapan dengan format angka sebanyak 4,40\%. Sementara item yang di dalam official website terdapat judul namun tidak ada isinya memiliki prosentase nilai sebesar 1,90\%. Dan untuk format pengungkapan yang paling rendah yaitu pengungkapan dengan menggunakan satuan moneter yang tidak mencapai angka $1 \%$, yaitu hanya sebesar $0,84 \%$.

Gambar 2 adalah hasil perhitungan human capital, structural capital, dan relational capital. Gambar 2 menunjukkan bahwa pengungkapan tertinggi dilakukan pada komponen structural capital yang mencapai angka $66 \%$.

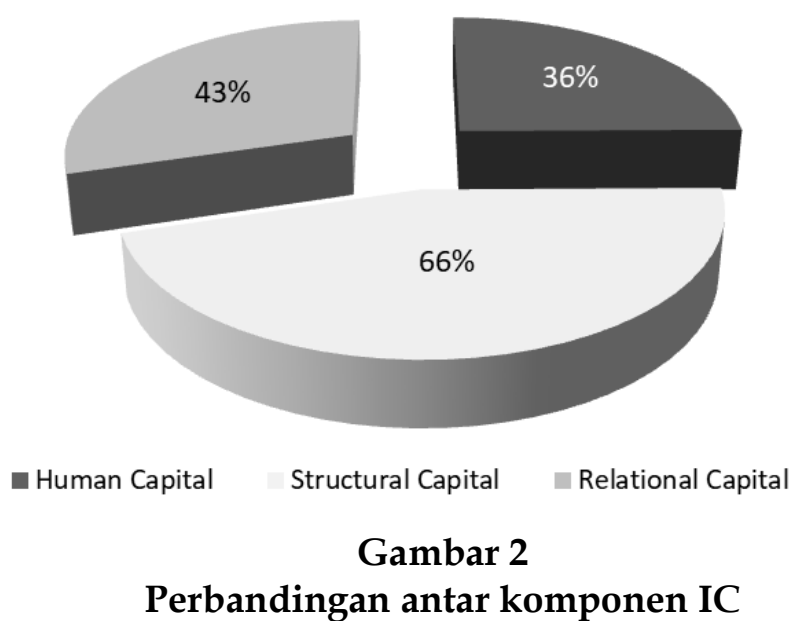

Komponen pada structural capital meliputi 18 item yang terkait dengan visi misi tujuan, strategi pencapaian VMT, sistem tata pamong, layanan kemahasiswaan, standar pembelajaran, sistem informasi pada sarana dan prasarana yang dimiliki tiap-tiap perguruan tinggi, hingga pada dana penelitian dan pengabdian masyarakat. Kemudian komponen kedua tertinggi yaitu pada relational capital yang memiliki persentase pengungkapan sebesar $43 \%$.

Pada komponen terakhir ini menganalisis kerjasama dalam bidang pendidikan, penelitian dan pengabdian kepada masyarakat yang dilakukan oleh perguruan tinggi vokasi baik itu kerjasama regional, nasional hingga kerjasama internasional. Hingga menganalisis dana yang digunakan untuk kerjasama oleh perguruan tinggi vokasi. Dan untuk komponen yang paling rendah persentase pengungkapannya yaitu komponen human capital dengan angka pengungkapan sebesar $36 \%$. Komponen ini menganalisis mulai dari jumlah dosen, jumlah tenaga kependidikan, jumlah mahasiswa, penelitian yang dilakukan dosen bersama mahasiswa, hingga pada prestasi yang dihasilkan oleh perguruan tinggi tesebut. Pada komponen ini memiliki item penilaian yang paling banyak dibandingkan dengan 2 komponen lainnya, item penilaian pada komponen ini yaitu sebanyak 30 item.

Berdasarkan dari hasil analisis yang telah dilakukan, yaitu melalui 5 tahapan, bahwa dalam pengungkapan modal intelektual yang dilakukan oleh 50 perguruan tinggi vokasi terbaik berdasarkan kemen- 
ristekdikti tahun 2019, maka diperoleh hasil bahwa dari 47 perguruan tinggi vokasi yang dapat diakses tersebut, belum ada yang mengungkapkan $100 \%$ modal intelektual yang dimiliki oleh masing-masing perguruan tinggi vokasi. Mouritsen et al. (2004) menyatakan bahwa intellectual capital disclosure dalam suatu laporan keuangan sebagai suatu cara untuk mengungkapkan bahwa laporan tersebut menggambarkan aktifitas yang kredibel, terpadu serta "true and fair".

Setelah dilakukan perhitungan data, maka didapatkan hasil bahwa pengungkapan modal intelektual paling tinggi dilakukan oleh Politeknik Negeri Pontianak, mengungkapkan sebanyak 44 item dari 60 item dari ketiga komponen penilaian. Sehingga persentase pengungkapan yang dilakukan oleh Politeknik Negeri Pontianak mencapai $73,33 \%$. Kemudian posisi kedua dengan jumlah pengungkapan yaitu sebanyak 43 item pengungkapan dilakukan oleh Politeknik Negeri Jakarta dan Politeknik Negeri Perkapalan Surabaya dengan persentase pengungkapan sebesar $71,66 \%$. Hal ini sesuai dengan penelitian yang dilakukan oleh Novitasari dan Ulum (2018) yang menyatkan Perusahaan yang mengungkapkan informasi di web cenderung lebih menguntungkan daripada perusahaan yang tidak.

Penggunaan Internet sebagai sarana untuk berkomunikasi dengan pasar kemudian didorong oleh daya saing di antara perusahaan industri. Selain ketiga perguruan tinggi dengan pengungkapan modal intelektual paling banyak, maka terdapat pula perguruan tinggi vokasi dengan pengungkapan paling rendah, yaitu dilakukan oleh Politeknik Negeri Ceper dengan jumlah item pengungkapan hanya 17 item dari 60 item, maka dari jumlah tersebut persentase pengungkapannya hanya mencapai $28,3 \%$. Dan untuk pengungkapan kedua terendah yaitu dilakukan oleh Politeknik Manufaktur Astra dengan hanya mengungkapkan 19 item dari 60 item. Maka persentase pengungkapan yang di dapatkan hanya berjumlah 31,6\%. Penelitian yang dilakukan Ulum et al. (2019) menyatakan bahwa pengungkapan modal intelektual yang dilakukan oleh perguruan tinggi di Indonesia lebih tinggi dibandingkan dengan pengungkapan modal intelektual perguruan tinggi yang dilakukan di Malaysia. Namun, baik perguruan tinggi di Indonesia maupun perguruan tinggi yang ada di Malaysia masih belum mengungkapkan modal intelektual yang dimilikinya secara penuh. Rata-rata pengungkapan yang dilakukan masih berkisar antara angka 50 persen.

Bontis et al. (2000) menyebutkan bahwa komponen human capital secara sederhana merepresentasikan individual knowledge stock suatu organisasi yang di representasikan oleh karyawannya. Komponen Human Capital merupakan pegungkapan yang memiliki presentase yang paling rendah diungkapkan oleh perguruan tinggi vokasi di Indonesia, yaitu sebanyak $36 \%$. Pada penelitian yang dilakukan oleh Puspitahati et al. (2011) bahwa komponen ini merupakan komponen yang pengukurannya lebih susah dibandingkan komponen yang lainnya. Dalam komponen ini tempat bersumbernya pengetahuan yang sangat berguna, keterampilan, berbagai kompetensi yang dimiliki oleh suatu organisasi maupun perusahaan. Human captial merupakan cerminan atau tolak ukur secara general terhadap kemampuan yang dimiliki oleh sumber daya yang ada di dalamnya.

Item yang paling banyak diungkapkan dalam komponen ini adalah item jumlah dosen. Menurut Sadalia dan Lubis (2015) Seorang dosen harus memahami modal intelektual agar mampu menghasilkan lulusan yang berkualitas. Anatan (2006) dalam penelitiannya mengemukakan bahwa modal SDM merupakan akumulasi dari nilai-nilai investasi dalam pelatihan pekerja atau karyawan dan kompetensi SDM. Dengan kata lain yaitu modal SDM merupakan solusi terbaik dalam mengelola dan mengembangkan SDM. Teori stakeholder 
menyatakan bahwa ketika manajer mampu mengelola perusahaannya secara maksimal, lebih spesifik lagi dalam upaya penciptaan nilai bagi perusahaan, maka itu artinya manajer tersebut sudah mampu aspek etika di dalam teori stakeholder.

Untuk komponen Structural Capital merupakan komponen yang paling besar prosentase pengungkapannya yaitu mencapai angka $66 \%$. Di dalam komponen ini yang paling besar item pengungkapannya yaitu pengungkapan Visi, Misi dan Tujuan perguruan tinggi. Item ini diungkapkan oleh semua perguruan tinggi vokasi yang official websitenya dapat diakses, yaitu sebanyak 47 perguruan tinggi vokasi. Menurut Ulum dan Novianty (2012) bahwa jika individu memiliki intelektual yang tinggi, tetapi jika organisasi dan sistem tidak mendukung intelektual tersebut berkembang dengan buruknya sistem dan prosedur tersebut, maka modal intelektual tidak akan dapat mencapai kinerja secara optimal dan potensi intelektual yang dimiliki tidak dapat dimanfaatkan secara maksimal. Ulum et al. (2019) mengatakan bahwa seorang karyawan berpotensi memiliki intelektualitas yang mumpuni jika sistem dan prosedur di dalam suatu organisasi tersebut juga baik.

Hasil dari perhitungan mengungkapkan bahwa relational capital memiliki angka pengungkapan terbsesar kedua setelah structural capital, yaitu sebesar $43 \%$. Hal ini dikarenakan bahwa komponen ini merupakan suatu langkah yang penting bagi tiap-tiap perguruan tinggi vokasi untuk dilaksanakan karena menjalin hubungan yang baik untuk mitra pada kancah regional, nasional, maupun internasional. Dalam komponen ini terdapat dua item yang di analisis yaitu kerjasama dalam bidang pendidikan, penelitian dan pengabdian kepada masyarakat. Dan item yang kedua yaitu jumlah dana yang dikeluarkan untuk menjalin kerjasama tersebut. Untuk item yang memiliki pengungkapan tertinggi yaitu pengungkapan pada item Kerjasama Nasional bidang pendidikan (RC4). Dimana, item ini diungkapkan oleh 44 perguruan tinggi vokasi, sehingga persentase pengungkapan pada item ini yaitu $88 \%$.

Item kedua adalah pengungkapan pada Kerjasama Nasional bidang Pengabdian kepada Masyarakat (RC6), dimana item ini diungkapkan oleh 38 perguruan tinggi vokasi, sehingga perolehan persentasenya yaitu sebesar $76 \%$. Hal ini terjadi dikarenakan sistem pendidikan saat ini lebih gencar untuk mencanangkan para mahasiswa dari perguruan tinggi vokasi maupun non-vokasi untuk dapat mempratekkan teori yang di dapatkan ke dalam kehidupan bermasyarakat. Berdasarkan penelitian dahulu yang dilakukan oleh Ulum et al. (2019) bahwa komponen ini merupakan kumpulan dari ekonomi, politik, dan hubungan kelembagaan yang dikembangkan dan ditegakkan antara universitas dan nonakademik, perusahaan, organisasi nonprofit, pemerintah daerah dan masyarakat pada umumnya.

\section{SIMPULAN}

Simpulan yang didapatkan dari peneitian ini yaitu, jumlah pengungkapan tertinggi dilakukan oleh Politeknik Negeri Pontianak dengan jumlah item pengungkapan sebanyak 44 item dari 60 item. Dimana komponen human capital diungkapkan sebanyak 19 item, Structural Capital sebanyak 15 item, dan kemudian Relational Capital sebanyak 10 item. Pengungkapan terendah dilakukan oleh Politeknik Negeri Ceper yang hanya mengungkapkan 17 item saja dari 60 item. Komponen Human Capital diungkapkan hanya 1 item saja dari 30 item, kemudian untuk komponen Structural Capital diungkapkan sebanyak 10 item dari 18 item dan yang terakhir untuk komponen Relational Capital diungkapkan sebanyak 6 dari 12 item. Berdasarkan hasil penelitian yang telah didapatkan, dimana komponen yang paling banyak diungkapkan oleh 47 Perguruan Tinggi Vokasi yaitu komponen Structural Capital. Hal ini juga didukung oleh peran dari Perguruan Tinggi Vokasi 
yang berfokus untuk mempersiapkan lulusan yang ahli dalam bidangnya. Maka dari itu, Perguruan Tinggi Vokasi memang sudah sepatutnya mendukung proses pembelajarannya dengan menyediakan Saran dan Prasarana Pembelajaran. Ini artinya, Perguruan Tinggi Vokasi harus mampu menyiapkan Infrastruktur seperti contohnya Laboraturium yang lengkap untuk mendukung pembelajaran yang berfokus pada $70 \%$ praktek.

Adapun keterbatasan yang ada selama penelitian ini berlangsung yaitu: Adanya official website beberapa perguruan tinggi vokasi yang tidak dapat diakses. Dalam melakukan content analysis, peneliti diharuskan melakukan akses terhadap official website secara teliti. Dan dalam hal ini potensi subjektifitas peneliti sangat sulit dihindarkan. Penelitian ini hanya mendeskripsikan bagaiman pengungkapan modal intelektual yang ada pada perguruan tinggi vokasi di Indonesia, sehingga tidak terdapat dokumen pembanding.

Berdasarkan dari keterbatasan yang ada selama penelitian berlangsung, maka adapun saran yang diberikan yaitu: Melakukan chek list berulang ketika melakukan content analysis untuk dapat meminimalisir subjektifitas. Melakukan content analysis secara teliti dan bersama agar hasilnya dapat dibandingkan dan meminimalisir kesalahan fatal penilaian item.

\section{DAFTAR PUSTAKA}

Anatan, L. 2006. Manajemen Modal Intelektual: Strategi Memaksimalkan Nilai Modal Intelektual Dalam Technology Driven Business. 5(2): 2-8.

Andriessen, D. 2005. Intellectual Capital Statements and Innovation. Diemen: Hogeschool INHOLLAND.

Antonella, S., dan V. Stefania. 2011. The intellectual capital report within universities: comparing experiences. European Integration: 618-624.

BAN PT. 2019. Panduan Penyusunan Laporan Kinerja Program Studi
Bezhani, I. 2010. Intellectual capital reporting at UK universities. Journal of Intellectual Capital 11(2): 179-207.

Bisogno, M., J. Dumay, F. M. Rossi, dan P. T. Polcini. 2018. Identifying future directions for IC research in education: a literature review. Journal of Intellectual Capital 19(1): 10-33.

Bontis, N. 1998. Intellectual capital: an exploratory study that develops measures and models. Management Decision 36(2): 63-76.

Bontis, N., W. C. C. Keow, dan S. J. J. o. i. c. Richardson. 2000. Intellectual capital and business performance in Malaysian industries. In Journal of Intellectual Capital: 2-9.

Brooking, A. 1996. Intellectual Capital: Core Assets for the Third Millennium. London: Enterprise Thomson Business Press.

Bukh, P. N., J. Mouritsen, M. R. Johansen, dan H. T. Larsen. 2001. Intellectual Capital Reporting and Knowledge Management in Systematic; Case from the book. Denmark: Udgivet Af Børsens Forlag.

Cañibano, L., dan M. P. Sánchez. 2009. Intangibles in universities: current challenges for measuring and reporting. Journal of Human Resource Costing $\mathcal{E}$ Accounting 13(2): 93-104.

Cañibano, L., dan P. Sánchez. 2004. Measurement, management and reporting on intangibles. State of the art. Accounting and Business Review 3(1): 3762.

Cricelli, L., M. Greco, M. Grimaldi, dan L. P. L. Dueñas. 2018. Intellectual capital and university performance in emerging countries: Evidence from Colombian public universities. Journal of Intellectual Capital 19(1): 71-95.

European Commission. 2007. Intellectual Capital Statement (InCaS). Berlin: The Fraunhofer Institute for Production Systems and Design Technology.

Harisnwati, R., I. Ulum, dan D. Syam. 2017. Pengaruh Intellectual Capital Performance Terhadapa Intensitas Pelaporan 
Modal Intelektual. Jurnal Reviu Akuntansi dan Keuangan 7(1).

Ikatan Akuntan Indonesia. 2015. PSAK Nomor 19 (revisi 2014) tentang Aset Takberwujud. Ikatan Akuntan Indonesia. Jakarta.

Itami, H., dan T. W. Roehl. 1987. Mobilizing Invisible Assets. Cambridge: Harvard University Press.

Leitner, K.-H. 2004. Intellectual capital reporting for universities: conceptual background and application for Austrian universities. Research evaluation 13(2): 129-140.

Leitner, K. H. 2002. Intellectual Capital Reporting for Universities: Conceptual background and application within the reorganisation of Austrian universities. In The Transparent Enterprise. The Value of Intangibles. Madrid, Spain: Autonomous University of Madrid Ministry of Economy.

Leitner, K. H., A. Curaj, S. Elena-Perez, J. Fazlagic, K. Kalemis, Z. Martinaitis, G. Secundo, M. A. Sicilia, dan K. Zaksa. 2014. A Strategic Approach for Intellectual Capital Management in European Universities: Guidelines for Implementation. Bucharest: UEFISCDI.

Maharani, N. B., dan Faisal. 2019. Modal Intelektual dan Kinerja Keuangan Perusahaan Jurnal Reviu Akuntansi dan Keuangan 9(1).

Moolman, S. 2010. Intellectual Capital: Measurement, Recognition And Reporting. Master Thesis, Accounting, Uniersity Of South Africa, Pretoria.

Mouritsen, J., P. N. Bukh, M. R. Johansen, H. T. Larsen, C. Nielsen, J. Haisler, dan B. Stakemann. 2003. Analysing Intellectual Capital Statements. Copenhagen, Danish Ministry of Science, Technology and Innovation. Denmark.

Mouritsen, J., P. N. Bukh, dan B. Marr. 2004. Reporting on Intellectual CapitalWhy, What, and How? Measuring Business Excellence 8(1): 46-54.

Novitasari, I., dan I. Ulum. 2018. Intellectual capital disclosure of Indonesian universities: a five ways numerical coding system. International Journal of Economics and Research 9(6): 1-9.

Nugroho, A. 2012. Faktor-faktor yang Mempengaruhi Intellectual Capital Disclosure. Accounting Analysis Journal 1 (2): 2-9.

Puspitahati, A., I. Ulum, dan A. Prasetyo. 2011. Analisis Pengungkapan Intellectual Capital pada Website Tiga Perguruan Tinggi di Indonesia In Seminar Nasional \& Call for Paper. Sidoarjo, Jawa Timur: FE Univ. Muhammadiyah Sidoarjo.

Raheja, V., dan A. Raheja. 1999. Cooperative education: A new look at the development of intellectual capital. Paper read at Proceeding of CEAWACE International Conference on Cooperative Education.

Ramírez, Y. 2013a. Importance of intellectual capital disclosure in Spanish universities. Intangible Capital 9(3).

- - - . 2013b. Intellectual capital management and reporting in European higher education institutions. Intangible Capital 9(1).

Ramirez, Y., dan S. Gordillo. 2014. Recognition and measurement of intellectual capital in Spanish universities. Journal of Intellectual Capital 15(1): 173-188.

Sadalia, I., dan A. N. Lubis. 2015. Discriminant Analysis of Intellectual Capital Model of State University in Medan.

Sanchez, M. P., dan S. Elena. 2006. Intellectual capital in universities; Improving transparency and internal management. Journal of Intellectual Capital 7(4): 529-548.

Sánchez, M. P., dan S. Elena. 2007. New Management in Higher Education Institutions: Introducing Intellectual Capital Approaches. Conradi Research Review 14(2): 71-87.

Sánchez, M. P., S. Elena, dan R. Castrillo. 2009. Intellectual capital dynamics in universities: a reporting model. Journal of Intellectual Capital 10(2): 307-324. 
Secundo, G., A. Margherita, G. Elia, dan G. Passiante. 2010. Intangible assets in higher education and research: mission, performance or both? Journal of Intellectual Capital 11(2): 140-157.

Sirojudin, G. A., dan I. Nazaruddin. 2014. Pengaruh Modal Intelektual dan Pengungkapannya Terhadap Nilai dan Kinerja Perusahaan. Jurnal Akuntansi dan Investasi 15(2): 78-88.

Starovic, D., dan B. Marr. 2003. Understanding Corporate Value - Measuring and Reporting Intellectual Capital. London: CIMA.

Stewart, T. A. 1997. Intellectual Capital. London: Nicholas Brealey Publishing.

Suhardjanto, D., dan M. J. J. Wardhani. 2010. Praktik intellectual capital disclosure perusahaan yang terdaftar di bursa efek Indonesia. 14(1): 71-85.

Sultanova, G., S. Svyatov, dan N. Ussenbayev. 2018. Transmitting competencies at universities in Kazakhstan: intellectual capital of teachers. Journal of Intellectual Capital 19(1): 112-134.

Suwarti, T., C. Mindarti, dan N. Setianingsih. 2016. Analisis Pengaruh Komisaris Independen, Konsentrasi Kepemilikan Terhadap Intellectual Capital Disclosure (ICD) Dan Kinerja Perusahaan. Paper read at Managing Local Resources to Compete in the Global Market-Forum Manajemen Indonesia VIII.

Tower, G., J. Plummer, B. Ridgewell, E. Goforth, dan S. Tower. 2008. Intellectual Capital Disclosure of Australian Universities. Financial Reporting, Regulation and Governance 7(1): 1-17.

Ulum, I. 2015. Intellectual Capital: Model Pengukuran, Framework Pengungkapan, dan Kinerja Organisasi. Malang: UMM Press.
- - - . 2019. Intellectual capital framework perguruan tinggi di Indonesia berdasarkan instrumen akreditasi program studi (IAPS) 4.0. Jurnal Reviu Akuntansi dan Keuangan 9(3): 309-318.

Ulum, I., dan A. Juanda. 2016. Metodologi Penelitian Akuntansi. Aditya Media Publishing. Yogyakarta.

Ulum, I., M. Malik, dan H. Sofyani. 2019. Analisis pengungkapan modal intelektual: Perbandingan antara universitas di Indonesia dan Malaysia. Jurnal Ekonomi dan Bisnis 22(1 April): 163 - 182.

Ulum, I., dan N. Novianty. 2012. Analisis Faktor-Faktor Yang Mempengaruhi Pengungkapan Intellectual Capital Pada Official Website Perguruan Tinggi Indonesia. In Simposium Nasional Akuntansi XV. Universitas Lambung Mangkurat Banjarmasin: Ikatan Akuntan Indonesia Kompartemen Akuntan Pendidik.

Ulum, I., dan R. Y. Pratiwi. 2012. Analisis Praktik Pengungkapan Intellectual Capital Pada Website Universitas Peraih QS-Star 2011. In Simposium Nasional Akuntansi \& Bisnis. Bandung: Universitas Widyatama.

Wang, J. C. 2008. Investigating market value and intellectual capital for S \& P 500. Journal of Intellectual Capital 9(4): 546563. 